\section{Forensic DNA typing dispute}

SIR - Lander and Budowle ${ }^{1}$, in declaring the end of the controversy over the forensic application of DNA technology, have presented a piece of propaganda that completely distorts the current situation in a very difficult matter at the nexus of science and law.

The errors of the article begin with its title. DNA patterns are not fingerprints, because unlike fingerprints, they are not idiotypes. The struggle to resolve the issues is not a "war", in which all "weapons" are fair, but for some of us, at least, an attempt to find out what is true. Most important, the controversy is most certainly not laid to rest but in some ways has become more urgent because of technical changes in the methods.

There are three outstanding issues. First, there is a very serious problem of laboratory reliability of DNA technology. Lander and Budowle dismiss this problem, assuring us that laboratory practice is now being scrupulously overseen by, of all agencies, the Federal Bureau of Investigation (FBI). It is the FBI laboratory, from which Dr Budowle comes, that failed to replicate its own DNA profiles in 12 per cent of samples, in an internal test of its procedures ${ }^{2}$, and which has consistently refused to allow independent third-party quality control of its work. It is ludicrous to set this fox to guard the henhouse.

The problem of laboratory reliability has been greatly exacerbated by the increasing use of PCR technology to amplify small samples. Typically, a large fresh sample of blood from the accused is worked on in the same laboratory or by the same technician as a minuscule scraping of blood or tissue from the crime scene. But, as everyone who uses the PCR technique knows, the probability of a false match by contamination of the minuscule crime scene sample, to be amplified, from the large sample taken from the accused, by mislabelling, aerosols, carelessly unchanged pipette tips and other similar laboratory sloppiness, is very great and many orders of magnitude greater than the tiny match probabilities calculated for forensic purposes. Moreover, the polymarker technology is incapable of detecting new alleles that may be possessed by the suspect or present in the crime scene sample, but which have not yet been included in the test array. In the absence of blind proficiency testing, qualitycontrol protocols and unannounced periodic checks designed and supervised by disinterested parties, the test results from federal, state and local crime laboratories, and private contract laboratories must be regarded as unreliable.

The second problem, that of correctly calculating probabilities when there is population heterogeneity, is dealt with by
Hartl in the accompanying letter.

Finally, because DNA profiles are not idiotypes, juries are asked to consider a numerical probability of matching. But there is an extensive literature about the ability of lay people to understand probability statements and to make decisions that accord with the logic of such statements (see, for example, ref. 3). The clear result of these investigations is that people not trained in quantitative methods cannot understand issues of statistical independence and the basic logic of probability statements. For example, it is common for people to believe that a 1 in 4 chance means that the event is bound to happen on the fourth trial. Nor can a one-time instruction by a judge be sufficient to correct these misunderstandings. Because juries are no more capable of interpreting probability statements than they are of interpreting any other piece of highly technical information, there are insuperable barriers to their use in the courts.

Given the DNA polymorphism in humans, it is within our reach to design sequencing methods that provide idiotypes, uniquely identifying individuals as real fingerprints do. Coupled with quality-control checks and proficiency testing by disinterested monitors, a system of forensic identification could be created that would on the one hand protect the innocent and, on the other, help to convict the guilty. So why does the FBI not devote its time and energy to such developments, instead of trying to defend and shore up a basically flawed system? Why did Lander and Budowle choose to embrace in the pages of a leading journal of science, just before Budowle is scheduled to appear before tens of millions on television as a witness for the prosecution in what is surely the most publicized crime since the assassination of John Kennedy? As the French say, it gives one to think.

\section{R. C. Lewontin}

Museum of Comparative Zoology,

Hanvard University, Cambridge,

Massachusetts 02138, USA

SIR - It is welcome news that the FBI, in an astonishing $180^{\circ}$ change of direction, has agreed to adopt the interim ceiling principle recommended by the National

\footnotetext{
1. Lander, E. \& Budowle, B. Nature 371, 735-738 (1994). 2. US vs Yee, 12 F. 3 d 540 (6th Circuit), 1993

3. Palmerini, M. The lllusion of Knowing (Wiley, Chichester 1993).

4. Lewontin, R. C. \& HartI, D. L. Science 254. 1745-1750 (1991)

5. Hartl, D. L. \& Lewontin, R. C. Science 260, 473-474 (1993).

6. Budowle, B., Monson, K. \& Giusti, A. M. Am. J. hum. Genet 55, 533-539.

Krane, D. E. etal.Proc. natn. Acad. Sci. U.S.A. 89 10583-10587 (1992)

8. Budowle, B. \& Monson, $\mathrm{K}$. in DNA Fingerprinting: The State of the Science (eds Pena, S. D. et al.) 171-191 (Birkhauser, Basel, 1993).
}

Research Council (NRC) ${ }^{1}$.

The reversal of policy is long overdue in view of the acceptance of the approach by many other DNA-typing agencies. The 'interim' ceiling principle, based on racial databases, is a stop-gap measure intended to be replaced by a more refined method based on databases from diverse ethnic groups. Alas, Lander and Budowle's announcement ending the DNA 'war' contains no indication that the FBI intends to implement the refined form of the ceiling principle. Furthermore, numerous not-so-subtle hints suggest that even the interim ceiling principle may soon be abandoned.

Ask yourself why an article about the adoption of the interim ceiling principle would attack the biological rationale for the method? The ceiling principle was designed to compensate for the genetic substructure that exists in human populations. But Lander and Budowle assert that the evidence for substructure in the Lewontin-Hartl paper ${ }^{4}$ is "flawed" (see ref. 5), and that the FBI's population surveys have found only "modest" differences among ethnic groups. How do these statements square with Budowle's previous admission ${ }^{6}$ that it is "universally accepted that substructure exists within major population groups"? Indeed, statistically significant differences among ethnic groups have been documented for markers used in DNA typing (see, for example, ref. 7), including many comparisons among ethnic groups in the FBI's own population surveys.

Statistical significance is an objective, unambiguous, universally accepted standard of scientific proof. When differences in allele frequencies among ethnic groups are statistically significant, it means that they are real - the hypothesis that genetic differences among ethnic groups are negligible cannot be supported. On what basis, then, does Budowle ignore substructure? Because the differences between ethnic groups are not "forensically significant" (p. 533 of ref. 6). When does a statistically significant difference become "forensically significant"? Well, "when the likelihood of occurrences of the DNA profile would be meaningfully different" 8 . And guess who decides whether differences are "meaningfully different"... ?

A short life for the ceiling principle is also intimated by the statement that the controversy over population substructure would have been disposed of several years ago had the FBI been given authority to set up a committee to rule on the issue. It would have "made short work of the population genetics issue, by clarifying, changing or discarding the original NRC recommendations" (ref. 1). In fact, the FBI has been granted such authority in the DNA Identification Act of 1994. Will "short work" be made of the interim ceiling principle? 